\title{
Requirement of the JIP1 scaffold protein for stress-induced JNK activation
}

\author{
Alan J. Whitmarsh, ${ }^{1,6,8}$ Chia-Yi Kuan, ${ }^{4,7,8}$ Norman J. Kennedy, ${ }^{1,8}$ Nyaya Kelkar, ${ }^{1,8}$ Tarik F. Haydar, ${ }^{4}$ \\ John P. Mordes, ${ }^{2}$ Michael Appel, ${ }^{2}$ Aldo A. Rossini, ${ }^{2}$ Stephen N. Jones, ${ }^{3}$ Richard A. Flavell, ${ }^{5}$ \\ Pasko Rakic, ${ }^{4}$ and Roger J. Davis ${ }^{1,9}$ \\ ${ }^{1}$ Howard Hughes Medical Institute and Program in Molecular Medicine, ${ }^{2}$ Program in Molecular Medicine and Division \\ of Diabetes, Department of Medicine, and ${ }^{3}$ Department of Cell Biology, University of Massachusetts Medical School, \\ Worcester, Massachusetts 01605, USA; ${ }^{4}$ Section of Neurobiology and ${ }^{5}$ Howard Hughes Medical Institute and Section \\ of Immunobiology, Yale University School of Medicine, New Haven, Connecticut 06520, USA
}

The c-Jun N-terminal kinase (JNK) signal transduction pathway is activated in response to the exposure of cells to environmental stress. Components of the JNK signaling pathway interact with the JIP1 scaffold protein. JIP1 is located in the neurites of primary hippocampal neurons. However, in response to stress, JIP1 accumulates in the soma together with activated JNK and phosphorylated c-Jun. Disruption of the Jip1 gene in mice by homologous recombination prevented JNK activation caused by exposure to excitotoxic stress and anoxic stress in vivo and in vitro. These data show that the JIP1 scaffold protein is a critical component of a MAP-kinase signal transduction pathway.

[Key Words: MAP kinase; scaffold; JIP1; JNK]

Received June 22, 2001; revised version accepted July 31, 2001.

The JNK (c-Jun N-terminal kinase) group of mitogenactivated protein (MAP) kinases phosphorylate the transcription factor c-Jun (Derijard et al. 1994; Kyriakis et al. 1994). JNK is activated in response to cellular stress and contributes to the apoptotic response (for review, see Davis 2000). Indeed, JNK is implicated in neuronal death following exposure to excitotoxins, during the progression of some neurodegenerative diseases (e.g., Huntington's), and during the recovery from stroke (Davis 2000). Therefore, JNK deficiency prevents c-Jun phosphorylation and causes resistance to stress-induced apoptosis (Yang et al. 1997b; Tournier et al. 2000). Similarly, mutation of the JNK phosphorylation sites on c-Jun (Ser ${ }^{63}$ and $\mathrm{Ser}^{73}$ ) prevents stress-induced neuronal apoptosis (Behrens et al. 1999). The JNK signal transduction pathway therefore contributes to physiological and pathophysiological neuronal responses to stress.

JNK is activated by dual phosphorylation on the tripeptide motif Thr-Pro-Tyr (Derijard et al. 1994). Two MAP-kinase kinases that activate JNK have been identified, MKK4 and MKK7 (for review, see Davis 2000). Disruption of the Mkk4 (Nishina et al. 1997; Yang et al. 1997a; Ganiatsas et al. 1998; Swat et al. 1998) or Mkk7

Present addresses: ${ }^{6}$ School of Biological Sciences, University of Manchester, Manchester, UK; ${ }^{7}$ Division of Developmental Biology, Cincinnati Children's Hospital Research Foundation, Cincinnati, OH 45229, USA. ${ }^{8}$ These authors contributed equally to this work.

${ }^{9}$ Corresponding author.

E-MAIL Roger.Davis@Umassmed.edu; FAX (508) 856-3210.

Article and publication are at http://www.genesdev.org/cgi/doi/10.1101/ gad. 922801 .
(Dong et al. 2000) genes causes defects in JNK activation in response to specific stimuli (Tournier et al. 2001). In contrast, simultaneous disruption of both $M k k 4$ and Mkk7 eliminates JNK activation in response to stress, indicating that the MKK4 and MKK7 protein kinases represent the major activators of JNK in vivo (Tournier et al. 2001). These MAP kinase kinases are activated, in turn, by phosphorylation by MAP kinase kinase kinases, including TAK1, TPL2, and members of the ASK, MLK, and MEKK groups (Garrington and Johnson 1999). These MAP-kinase kinase kinases serve to integrate signals mediated by upstream signaling molecules (e.g., Rho family GTPases) to the activation of the protein kinase cascade that leads to JNK activation (for review, see Davis 2000).

The protein kinases that form the JNK signal transduction pathway may be organized into modules (Whitmarsh and Davis 1998). The kinases may function as a series of sequential binary complexes (Xia et al. 1998). Alternatively, one of the protein kinases may serve to bind the other protein kinases to form a functional module (Cheng et al. 2000). It is also possible that scaffold proteins may assemble a functional signaling module (Whitmarsh and Davis 1998). Studies of yeast have established that the protein kinase components of the mating MAP-kinase pathway interact with the scaffold protein Ste5p and that this interaction is essential for the formation of a functional signaling module (Elion 2000). Recent studies of the JNK signal transduction pathway have led to the identification of two types of potential scaffold proteins, $\beta$-arrestin and JIP. 
The $\beta$-arrestin scaffolds are implicated in signaling by G protein coupled receptors (GPCR). These receptors bind ligand and are phosphorylated by GPCR kinases (GRK; Pitcher et al. 1998). The phosphorylated receptors can engage the scaffold protein $\beta$-arrestin-2 (Miller and Lefkowitz 2001), which serves as a site of assembly for a functional JNK signaling module (McDonald et al. 2000). The $\beta$-arrestin- 2 scaffold protein directly binds JNK3 and ASK1 at different sites and indirectly interacts with MKK4. This scaffold protein may therefore serve to recruit a JNK signaling module to activated seven transmembrane-spanning receptors.

The JIP group of scaffold proteins (also known as IB/ JSAP) bind to JNK, MKK7, and to members of the mixedlineage protein kinase (MLK) group (Dickens et al. 1997; Bonny et al. 1998; Whitmarsh et al. 1998; Ito et al. 1999; Yasuda et al. 1999; Kelkar et al. 2000; Negri et al. 2000). The Jip1 gene is expressed in many tissues, including neurons, neuroendocrine cells (e.g., the $\beta$ cells of the islets of Langerhans), lung, kidney, and in several other tissues at lower levels. In contrast, the JIP2 and JIP3 proteins are selectively expressed in neurons and in neuroendocrine cells, but low levels can be detected in some other tissues. In vitro biochemical assays and transfection assays show that JNK, MKK7, and MLK bind to separate sites on JIP proteins (Whitmarsh et al. 1998). These assays also show that JIP proteins potentiate the activation of JNK (Whitmarsh et al. 1998). Therefore, JIP proteins represent putative scaffolds that may contribute to the activation of JNK in vivo (Whitmarsh and Davis 1998).

Although biochemical studies and transfection assays indicate that these putative JNK scaffold proteins can potentiate JNK activation in cultured cells, the function of these scaffold proteins in vivo has not been established (Davis 2000). The purpose of this study was to examine the role of the JIP1 scaffold protein. A null allele of the Jip1 gene in mice was created by homologous recombination. We show that JIP1 is required for stressinduced activation of JNK in hippocampal neurons in vivo and in vitro. In addition, we show that the JIP1 protein accumulates in the perinuclear region of hippocampal neurons following exposure to stress. These data show that JIP1 acts as a dynamically regulated scaffold protein for a JNK signaling module in vivo.

\section{Results}

\section{IIP1 is located in the neurites of primary neurons}

We prepared primary cultures of murine cortical neurons to study the subcellular distribution of JIP1. Immunofluorescence analysis using an antibody to JIP1 showed a low level of diffuse staining in the cytoplasm, including the soma and the extended neurites. Interestingly, JIP1 appeared to accumulate in the growth cones at the tips of extended neurites (Fig. 1A). The localization of JIP1 at the ends of extended neurites in primary neurons is similar to the accumulation of JIP proteins in the cell surface projections of cultured cells (Meyer et al. 1999; Yasuda et al. 1999; Kelkar et al. 2000). Immunocytochemical analysis of the brain indicates that JIP1 also accumulates at synapses (Pellet et al. 2000).

The localization of JIP1 at the ends of extended neurites is consistent with a possible interaction of JIP1 with the kinesin group of microtubule motor proteins. Kine$\sin -1$ is a plus end-directed microtubule motor protein (Hollenbeck 2001) and may contribute to the accumulation of JIP1 at the ends of extended neurites in the growth cones of murine primary neurons. To test whether JIP1 interacts with kinesin-1 in murine brain, we performed coimmunoprecipitation analysis. Endogenous JIP1 was found to coprecipitate with endogenous kinesin light chain in experiments using murine brain extracts (Fig. 1C). This was confirmed using recombinant proteins expressed in cultured cells (Fig. 1D). The TPR region of kinesin light chain and the C-terminal region of JIP1 were necessary and sufficient for the interaction (Fig. 1E,F). This role of the TPR region of kinesin light chain reflects the ability of TPR domains in other proteins to function as a protein interaction module (Groves and Barford 1999). Together, these data confirm observations reported after this study was completed indicating that JIP proteins may be cargoes for kinesin-1 (Bowman et al. 2000; Verhey et al. 2001).

\section{JIP1 accumulates in the perinuclear region of neurons following exposure to stress}

The JNK signal transduction pathway is activated when neurons are exposed to environmental stress. Anoxic stress therefore causes JNK activation in primary neurons. Activated JNK was detected with an antibody to phospho-(pThr $\left.{ }^{183} \mathrm{pTyr}^{185}\right)$-JNK. Immunofluorescence analysis showed that a low level of activated JNK was detected in control hippocampal neurons (Fig. 2G) and that increased amounts of activated JNK were detected following anoxic stress (oxygen and glucose deprivation or OGD; Fig. 2H). The activation of JNK was associated with markedly increased phosphorylation of c-Jun (Fig. 2I,J). Immunofluorescence analysis indicated that most of the activated JNK was detected in the cytoplasm surrounding the nucleus, but some activated JNK was also observed in the nucleus (Fig. 2G,H). In contrast, phosphorylated c-Jun was found to accumulate primarily in the nucleus (Fig. 2I,J). This difference in the subcellular location of activated JNK and phosphorylated c-Jun raises questions about the dynamic nature of protein localization within the cell (e.g., nuclear/cytoplasmic recycling). In particular, it is striking that the scaffold JIP1 is peripherally located in the neurites of unchallenged neurons, whereas activated JNK is primarily detected in the perinuclear region.

The presence of JIP1 in the extended neurites and activated JNK in the perinuclear region of primary hippocampal neurons (Fig. 2) indicates that the scaffold protein JIP1 may be located in a different subcellular compartment from activated JNK. To test this hypothesis, we examined the subcellular distribution of JIP1 in cells exposed to OGD stress. Immunofluorescence analysis 
A
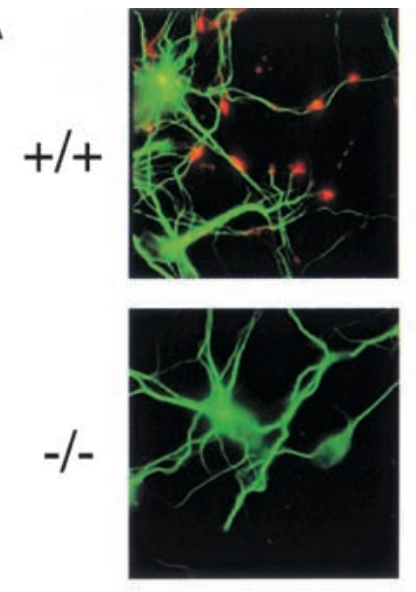

JIP1 / Tubulin
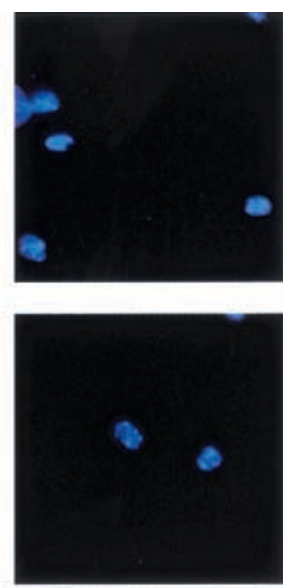

DAPI

B

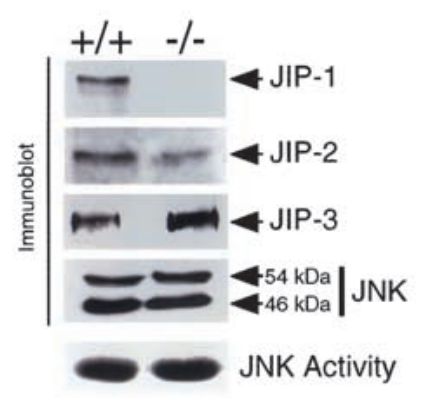

C

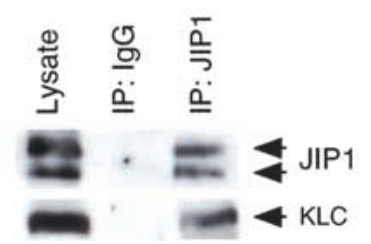

D

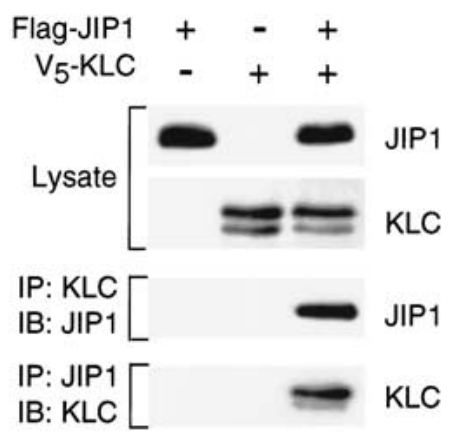

E

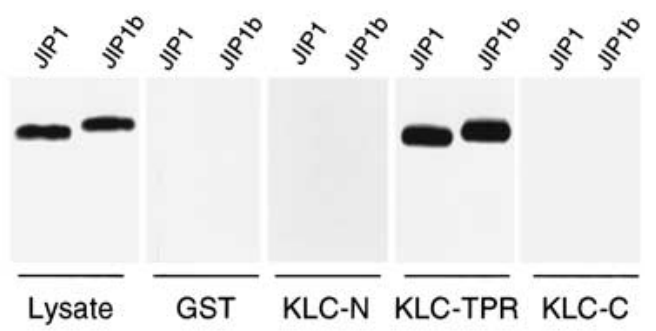

F

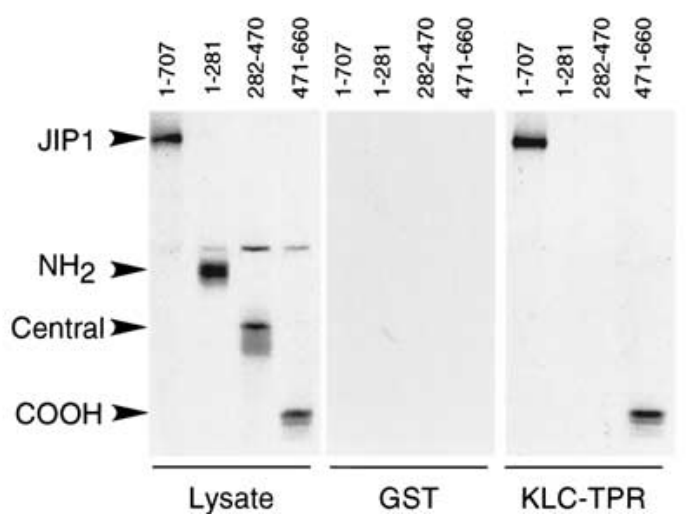

Figure 1. Subcellular distribution of JIP1. (A) Cortical neurons isolated from wild-type and Jip1 $1^{-/-}$mice were examined by conventional immunofluorescence microscopy by staining with antibodies to JIP1 (red) and $\alpha$-tubulin (green). DNA was stained with 4,6-diamidino-2-phenylindole (DAPI; Molecular Probes). (B) Neuronal cell lysates were examined by immunoblot analysis using antibodies to JNK, JIP-1, JIP-2, and JIP-3. JNK activity was measured in an in vitro kinase assay using the substrates GST-c-Jun and $\left[\gamma^{-}{ }^{32} \mathrm{P}\right]$ ATP. $(C)$ Coimmunoprecipitation analysis of JIP1 and kinesin. Endogenous JIP1 was immunoprecipitated (IP) from mouse brain extracts using a monoclonal antibody to JIP1. Control immunoprecipitations were performed using the M2 monoclonal antibody to the Flag epitope (IgG). The presence of endogenous kinesin light chain (KLC1) in the immunoprecipitate was examined by immunoblot (IB) analysis. (D) Coimmunoprecipitation using epitope-tagged JIP1 and KLC expressed in COS cells. Immunoprecipitation (IP)immunoblot (IB) analysis showed interactions between Flag-tagged JIP1 and $\mathrm{V}_{5}$-tagged KLC. (E) Deletion analysis of KLC. JIP1 and JIP1b were translated in vitro in the presence of $\left[{ }^{35} \mathrm{~S}\right]$ methionine and incubated with immobilized GST or GST-KLC fusion proteins (KLC-N, KLC-TPR, and KLC-C correspond to residues 1-198, 192-422, and 408-573, respectively). Bound JIP1 proteins were detected by SDS-PAGE and autoradiography. (F) Deletion analysis of JIP1. Full-length and truncated JIP1 molecules were translated in vitro in the presence of $\left[{ }^{35} \mathrm{~S}\right]$ methionine and incubated with immobilized GST or a fusion protein consisting of GST fused to the TPR region of KLC. Bound JIP proteins were detected by SDS-PAGE and autoradiography.

showed that most of the JIP1 was observed as punctate staining in the neurites of unchallenged hippocampal neurons, but low amounts of diffuse JIP1 were detected in the soma (Fig. 2A,C). In contrast, following OGD challenge most of the JIP1 was detected as punctate staining surrounding the nucleus (Fig. 2B,D). These data suggest that the subcellular localization of JIP1 is altered following exposure to stress. To test whether the apparent redistribution of JIP1 might be an indirect consequence of neurite retraction following stress, we examined the lo- calization of synaspsin I in neurons following OGD challenge. It was found that synapsin I remained localized to neurites when JIP1 accumulated in the perinuclear region of hippocampal neurons following exposure to stress (Fig. 2E,F). Together, these data indicate that the stress-induced accumulation of JIP1 in the perinuclear region precedes neurite retraction. The scaffold protein JIP1 is therefore present in the same subcellular compartment as activated JNK in hippocampal neurons following exposure to stress. These data are consistent with 

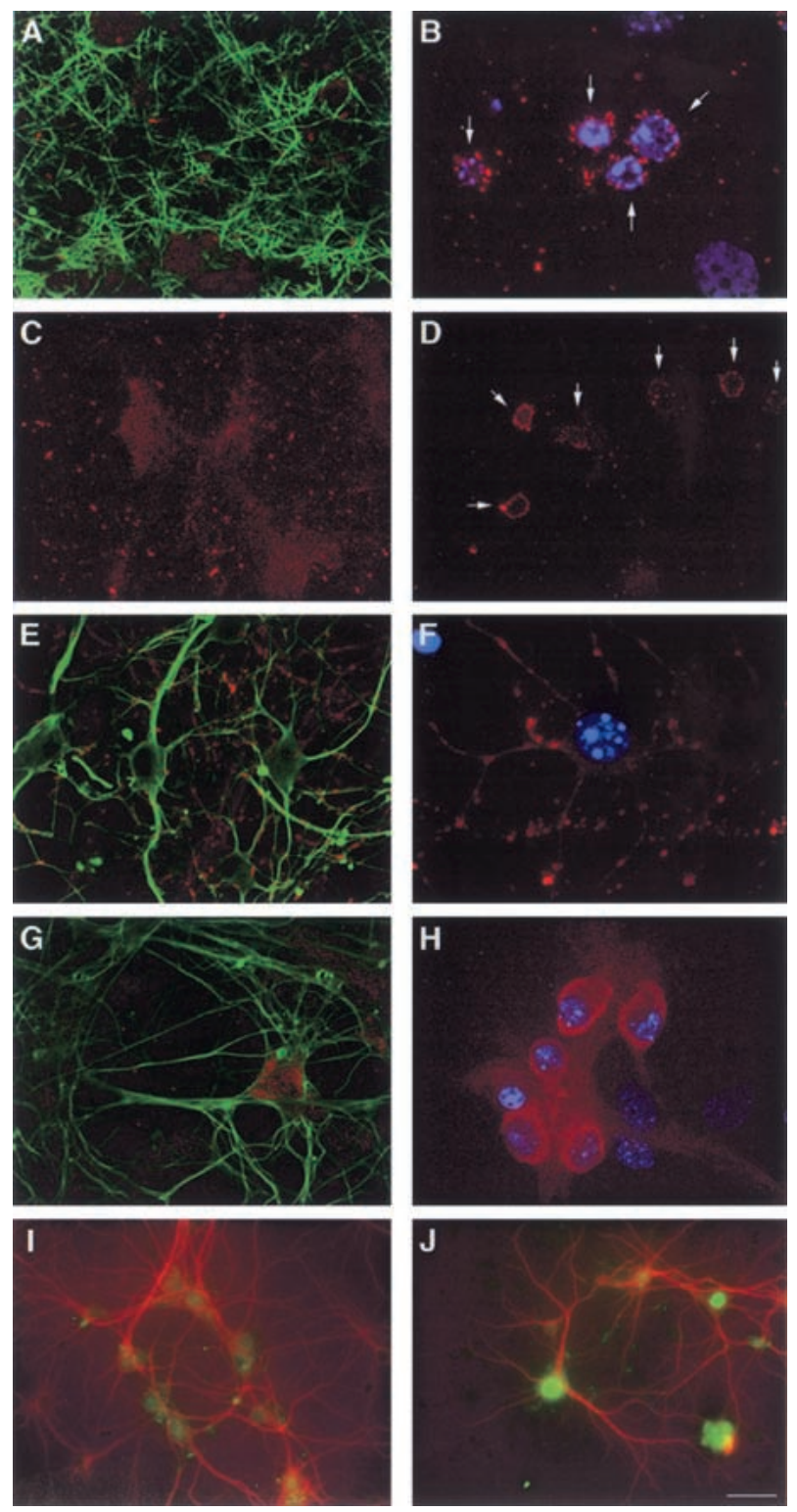

Figure 2. JIP1 accumulates in the perinuclear region following exposure to stress. Wild-type hippocampal neurons were exposed to OGD challenge $(4 \mathrm{~h})$, allowed to recover $(12 \mathrm{~h})$, and examined by immunofluorescence microscopy. $(A-D)$ JIP1 (red) was examined in control $(A, C)$ and OGD-challenged $(B, D)$ hippocampal neurons. The cells were costained with $(A)$ neuronspecific $\beta$-tubulin (green) and $(B)$ bis-benzimide (blue). Punctate staining of JIP1 in control neurons was present in the neurites $(A, C)$. In contrast, punctate staining of JIP1 was found in the perinuclear region (arrows) in OGD-challenged neurons $(B, D)$. $(E, F)$ Synapsin 1 (red) was examined in control $(E)$ and OGDchallenged $(F)$ neurons costained for $\beta$-tubulin (green) and DNA (blue), respectively. $(G, H)$ Phospho-(pThr ${ }^{183}$ pTyr $\left.^{185}\right)$-JNK (red) was examined in control $(G)$ and OGD-challenged $(H)$ neurons costained for $\beta$-tubulin (green) and DNA (blue), respectively. $(I, J)$ Phospho-Jun (green) was examined in control $(I)$ and OGDchallenged $(J)$ neurons costained for MAP2 (red) by conventional immunofluorescence microscopy. The phospho-c-Jun antibody was specific for c-Jun phosphorylated by JNK on $\mathrm{Ser}^{73}$. Scale bar in $I, 40 \mu \mathrm{m}$ (panels $A, B, E-H$ ), $25 \mu \mathrm{m}$ (panels $I, J)$; and $16 \mu \mathrm{m}$ (panels $C, D$ ). the possibility that JIP1 may act as a scaffold protein for a stress-activated JNK signaling module.

Coimmunoprecipitation analysis showed that MLK, MKK7, and JNK interact with JIP1 in nonstimulated cells (Whitmarsh et al. 1998). These data indicate that JIP1 preassembles a JNK signaling module in nonstimulated cells. This preassembled module includes only a small population of the total MKK7 and JNK molecules within the cell because immunofluorescence analysis showed that JNK and MKK7 did not extensively colocalize with JIP1 in the neurites of nonstimulated neurons (data not shown). Following activation, increased coimmunoprecipitation of JNK with JIP1 was detected (data not shown). Therefore, cell stimulation causes changes in the assembly of the JNK module by the JIP1 scaffold protein. These changes may be related to the function of JIP1 as a potential scaffold protein.

\section{Targeted disruption of the Jip1 gene in mice}

To test the hypothesis that the scaffold protein JIP1 is required for stress-induced JNK activation, we examined the effect of JIP1 deficiency using a targeted gene-disruption strategy. We isolated the Jip1 gene from a mouse strain 129/Sv genomic library. Sequence analysis showed that the gene includes 12 exons. Two different murine JIP1 cDNAs have been molecularly cloned (Dickens et al. 1997; Whitmarsh et al. 1998). These cDNAs encode a full-length protein (JIP1b) and a protein with an in-frame deletion of 47 amino acids in the C-terminal region (JIP1). These JIP1 proteins appear to result from alternative splicing of sequences between exons 8 and 9. A replacement targeting vector for homologous recombination was designed to delete exon 3 , which encodes the JNK binding domain (JBD) of JIP1 (Fig. 3A). The disrupted allele contains a neomycin-resistance cassette that is transcribed in the reverse orientation within the Jip1 gene. Three heterozygous Jip1 embryonic stem cell clones were identified by Southern blot analysis. Two of these clones were injected into C57BL/6 blastocysts to obtain chimeric mice that transmitted the mutated Jip1 allele through the germ line. Heterozygous mice were crossed to obtain mice that were homozygous for the disrupted Jip1 allele (Fig. 3B). The frequency of genotypes obtained corresponds to the expected Mendelian inheritance. Immunoblot analysis of brain tissue isolated from Jip $1^{-/-}$mice showed that JIP1 was not detected in the Jip1 $^{-/-}$animals (Fig. 3C). These data show that the Jip1 mutation corresponds to a null allele. The Jip $1^{-/-}$mice were viable and fertile with no detected developmental defects. Aging studies conducted during a 30-mo period showed that the life spans of Jip $1^{-/-}$and wild-type mice were similar.

Primary neurons were prepared and examined by immunofluorescence analysis. JIP1 was not detected in primary neurons isolated from Iip $1^{-1-}$ mice (Fig. 1A). Furthermore, immunoblot analysis confirmed that JIP1 was not present in Jip1 $1^{-/-}$primary neurons (Fig. 1B). This analysis also showed that JIP1-deficiency did not cause changes in the expression of JNK or JIP3 (Fig. 1B). How- 


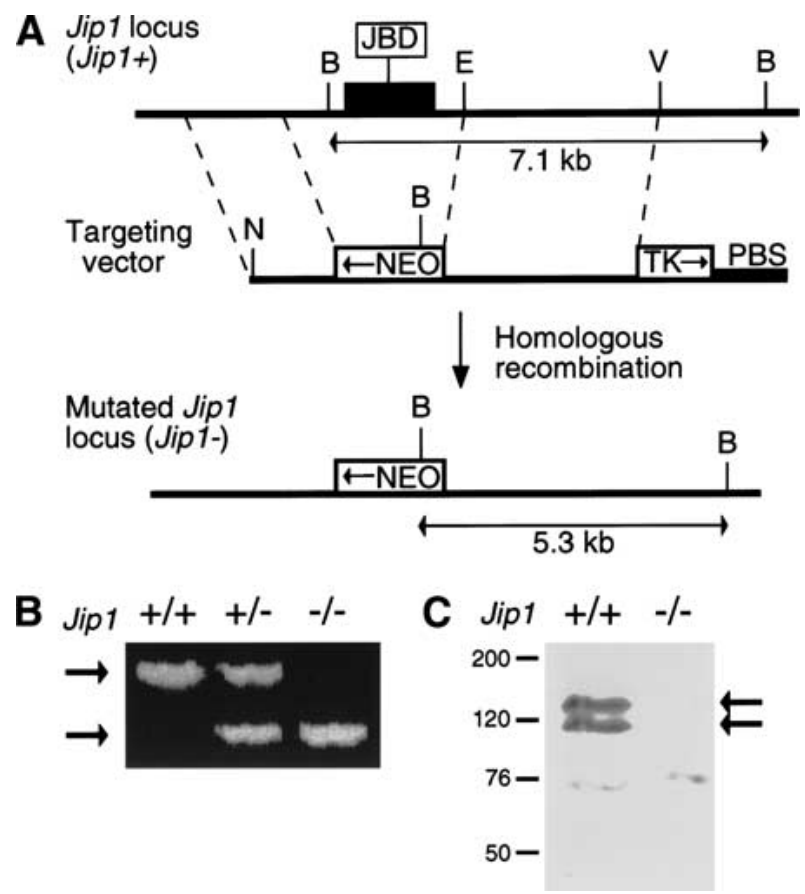

Figure 3. Generation of Jip $1^{-/-}$mice. (A) Strategy for the disruption of the Jip1 gene. Exon 3 encodes the JNK-binding domain (JBD) of JIP1 and was replaced with a neomycin-resistance gene (NEO) in the reverse orientation by homologous recombination. Restriction enzyme sites are indicated (B, BgII; E, EcoRI, $\mathrm{V}, E c o R V ; \mathrm{N}$, Not1). (B) Identification of JIP1-deficient mice. Genomic DNA isolated from wild-type $(+/+)$, heterozygous $(+)$ - ), and homozygous (-/-) knockout mice was examined by PCR. The wild-type and disrupted alleles are indicated. $(C)$ Expression of the JIP1 protein. Brain tissue from wild-type $(+/+)$ and knockout $(-/-)$ mice was examined by immunoblot analysis using an antibody to JIP1.

ever, a slightly reduced amount of JIP2 was detected in Jip $1^{-/-}$neurons (Fig. 1B). In vitro protein kinase assays showed that JNK activity in primary neurons from wildtype and Jip1 $1^{-/-}$mice was similar (Fig. 1B). Following exposure to ultraviolet radiation or the drug anisomycin, no difference in JNK activity between wild-type and Jip $1^{-/-}$neurons was detected. These data show that JIP1 deficiency does not cause obvious compensating changes in JNK or the putative scaffold proteins JIP2 and JIP3.

\section{IIP1 is not required for the Reelin signaling pathway or pancreatic $\beta$-cell function}

It has been reported that JIP1 is required for insulin and GLUT2 expression by pancreatic $\beta$-cells (Bonny et al. 1998 ), that JIP1 regulates $\beta$-cell apoptosis (Bonny et al. 2000), and that Jip1 is a candidate type II diabetes gene in humans (Waeber et al. 2000). These data suggest that the Jip $1^{-/-}$mice may have severe diabetes. However, islet morphology and expression of the hormones insulin and glucagon appeared to be normal in Jip $1^{-/-}$mice (data not shown). Furthermore, comparison of Jip $1^{-/-}$and Jip $1^{+/+}$ mice showed no differences in blood glucose concentra- tions or performance in glucose tolerance tests (data not shown). It therefore appears that, contrary to expectations (Bonny et al. 1998, 2000; Waeber et al. 2000), the loss of JIP1 function in mice may not be a direct cause of diabetes.

It has been reported that the PTB domain of JIP1 interacts with members of the LDL receptor-related group of proteins (Stockinger et al. 2000). ApoER2 (together with the related protein VLDL-R) acts as a receptor for the extracellular matrix protein Reelin. Disruption of the Reelin gene in mice causes altered brain development characterized by an inversion of the cortical layering of neurons (D'Arcangelo et al. 1995). This defect was also observed in ApoER2 $2^{-/-}$mice, although disruption of the genes that encode both Reelin receptors (ApoER2 and $V L D L-R$ ) caused a more profound phenotype (Trommsdorff et al. 1999). To test whether the recruitment of JIP1 by ApoER2 is critical for the Reelin signaling pathway (Stockinger et al. 2000), we performed histological analysis of Jip1 $1^{-/-}$brains. No lamination defects were detected in the cerebral cortex or cerebellum (data not shown). Neuronal migration was examined by birth-date analysis using BrdU labeling at embryonic day (E)15.5. Immunocytochemical analysis of BrdU-labeled neurons at 10 days after birth showed a normal distribution in layers 2 and 3 of the cerebral cortex in both wild-type and Jip $1^{-/-}$ mice (data not shown). These data suggest that JIP1 is not essential for Reelin/ApoER2 function during brain development.

\section{JIP1 is required for JNK activation in response to excitotoxic stress}

Exposure to the excitotoxin kainate causes increased expression of AP-1 proteins (c-Jun and c-Fos), JNK activation, and phosphorylation of c-Jun in the hippocampus (Yang et al. 1997b). Gene-targeting studies in mice show that although JNK is not required for increased expression of AP-1 proteins, JNK is required for AP-1 transcription activity and increased c-Jun phosphorylation following exposure to kainate (Yang et al. 1997b). JIP1 represents a putative scaffold protein that may coordinate the activation of the JNK signaling module during this response (Whitmarsh et al. 1998). To test this hypothesis, we examined the effect of excitotoxic stress in mice exposed to kainate (Yang et al. 1997b). Immunohistochemical analysis showed that kainate caused a similar increase in expression of c-Jun protein in the hippocampus of wild-type and Jip1 ${ }^{-/-}$mice (Fig. 4A,C,E). Activated JNK was detected with an antibody to phospho$\left(\mathrm{pThr}^{183} \mathrm{pTyr}^{185}\right)$-JNK. A small amount of activated JNK was detected in the cytoplasm of $\operatorname{Iip}^{-/-}$and wild-type hippocampal neurons (Fig. 4B). Increased amounts of phospho-JNK were detected in both the nucleus and the cytoplasm of wild-type hippocampal neurons following treatment with kainate (Fig. 4D). In contrast, following treatment with the same dosage of kainate, JNK activation was markedly attenuated in the hippocampal neurons of Jip $1^{-/-}$mice (Fig. 4F) despite a comparable level of c-Jun protein expression (Fig. 4E). These data show that 
Figure 4. Comparison of c-Jun and activated JNK in the hippocampus following exposure to excitotoxic stress. $(A, C, E) \mathrm{c}$ Jun was detected in the hippocampus of mice by immunocytochemistry using an antibody to c-Jun. $(B, D, F)$ Activated JNK was detected in the hippocampus by immunocytochemistry with an antibody to phospho-(pThr $\left.{ }^{183} \mathrm{pTyr}^{185}\right)$-JNK. c-Jun in nonstressed wild-type mice was restricted to the dentate gyrus (DG) $(A)$, and a low amount of phospho-JNK was detected in the cytoplasm, but not the nucleus, of hippocampal neurons $(D)$. The expression of c-Jun and phospho-JNK in unchallenged Iip $1^{-1-}$ mice was indistinguishable from that in wild-type mice. Five hours after a systemic injection of $30 \mathrm{mg} / \mathrm{kg}$ of kainate, a marked increase in c-Jun protein was detected in the hippocampus of both wildtype $(C)$ and $J i p 1^{-/-}(E)$ mice. However, although a marked increase in phospho-JNK in the cytoplasm and nucleus of the hippocampal neurons was detected in wildtype mice following treatment with kainate $(D)$, phospho-JNK was only slightly induced in the cytoplasm, but not the nucleus, following kainate challenge of Jip $1^{-1-}$ mice $(F)$. Scale bar in $F, 240 \mu \mathrm{m}$ (panels $A, C, E$ ) and $60 \mu \mathrm{m}$ (panels $B, D, F$ ).
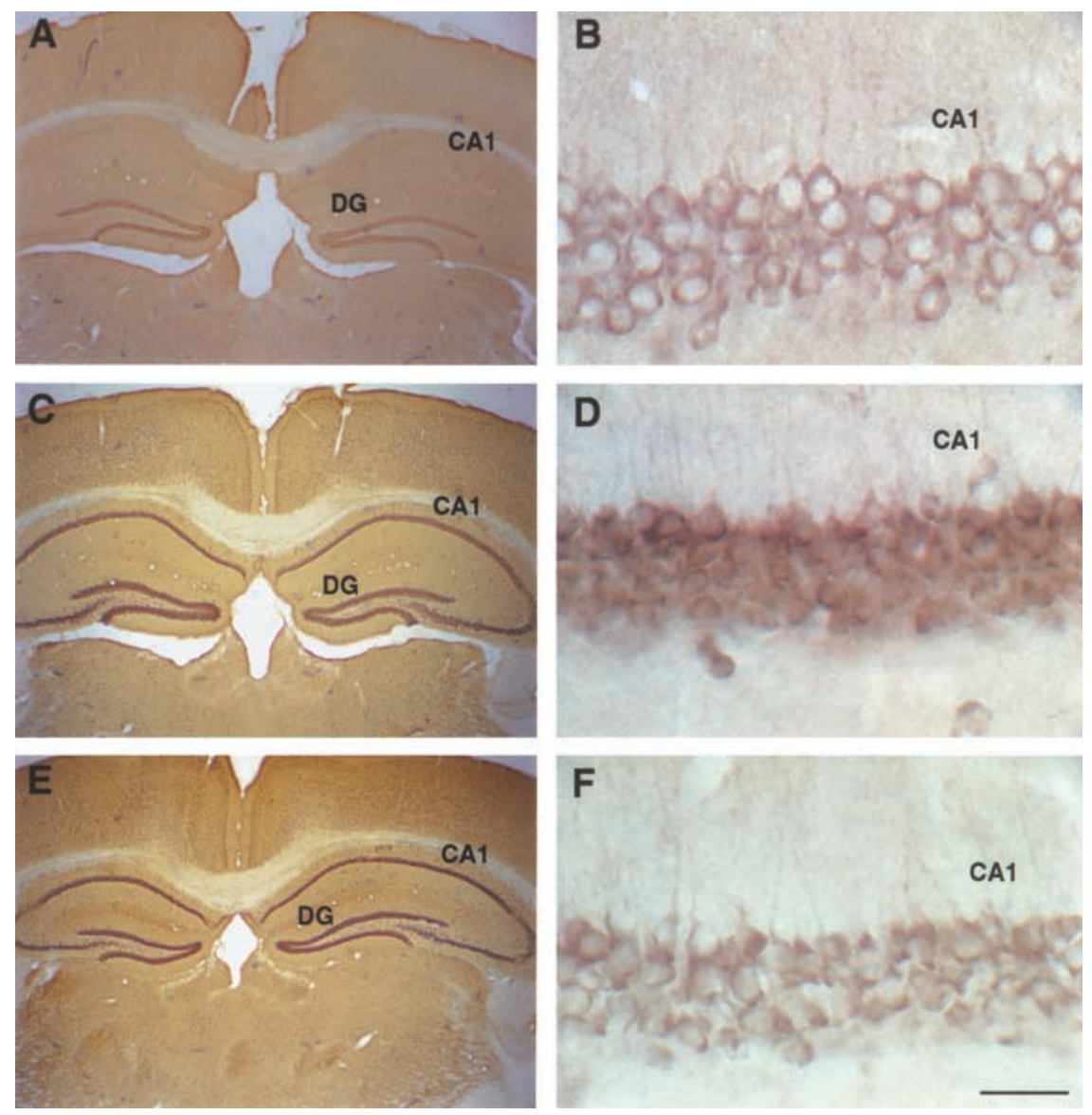

JIP1 is required for the normal regulation of JNK in hippocampal neurons exposed to excitotoxic stress.

\section{IIP1 deficiency causes reduced stress-induced apoptosis}

The JNK signal transduction pathway can mediate an apoptotic response (Xia et al. 1995; Yang et al. 1997b; Tournier et al. 2000). Indeed, gene-targeting studies indicate that both JNK and c-Jun phosphorylation are required for apoptosis mediated by the excitotoxin kainate (Yang et al. 1997b; Behrens et al. 1999). Therefore, we tested whether kainate-stimulated apoptosis of hippocampal neurons in vivo (Simonian et al. 1996) was altered in Jip1 ${ }^{-1-}$ mice (Fig. 5). Analysis of wild-type mice $(n=33)$ showed that kainate caused marked lesions in the CA3 subfield of the hippocampus (Fig. 5A). These lesions contained TUNEL-positive apoptotic cells (Fig. 5B) and sprouting of GFAP-positive astroglial fibers (Fig. 5C). JIP1-deficient mice $(n=34)$ showed a reduced extent of kainate-induced lesions in the CA3 subfield of the hippocampus (Fig. 5D-F). Quantitative analysis of Nissl's stained sections (Fig. 5A,D) showed that the average width of CA3 lesions in the wild-type and Jip1 $1^{-1-}$ animals was $343 \pm 80 \mu \mathrm{m}$ and $132 \pm 30 \mu \mathrm{m}($ mean $\pm \mathrm{SD})$, respectively. These data indicate that Jip $1^{-/-}$mice, like JNK-deficient mice and c-Jun phosphorylation-deficient mice, are resistant to kainate excitotoxicity in the CA3 subfield of the hippocampus in vivo. This conclusion was confirmed by studies of wild-type and Jip $1^{-/-}$primary hippocampal neurons cultured in vitro. The JIP1deficient neurons were found to be resistant to kainate treatment (Fig. 6). The amount of neuroprotection was similar to JNK3-deficient hippocampal neurons (Fig. 6G). Together, these data indicate that JIP1 deficiency causes reduced kainate-stimulated apoptosis of hippocampal neurons in vivo and in vitro.

To test whether the resistance to stress-induced JNK activation and apoptosis was specific to kainate excitotoxicity, we examined the effect of a different form of stress on wild-type and Jip $1^{-/-}$hippocampal neurons. Incubation of neurons in glucose-free medium with a reduced oxygen $(1 \%)$ environment for $4 \mathrm{~h}$ (oxygen-glucose deprivation; OGD) causes caspase-3 activation and apoptosis during subsequent culture in normal medium (Nath et al. 1998). The basal level of activated JNK in wild-type and $\mathrm{Jip}^{-1-}$ hippocampal neurons was similar. However, OGD challenge caused marked activation of JNK in wild-type neurons, but only a slight increase of JNK activation in JIP1-deficient neurons (Fig. 7C,D). Time-course analysis showed that the defect in JNK activation in Jip $1^{-/-}$neurons was not caused by delayed JNK activation. The Jip1 $1^{-/}$neurons were also resistant to the apoptotic effects of OGD stress. Thus, JIP1-defi- 

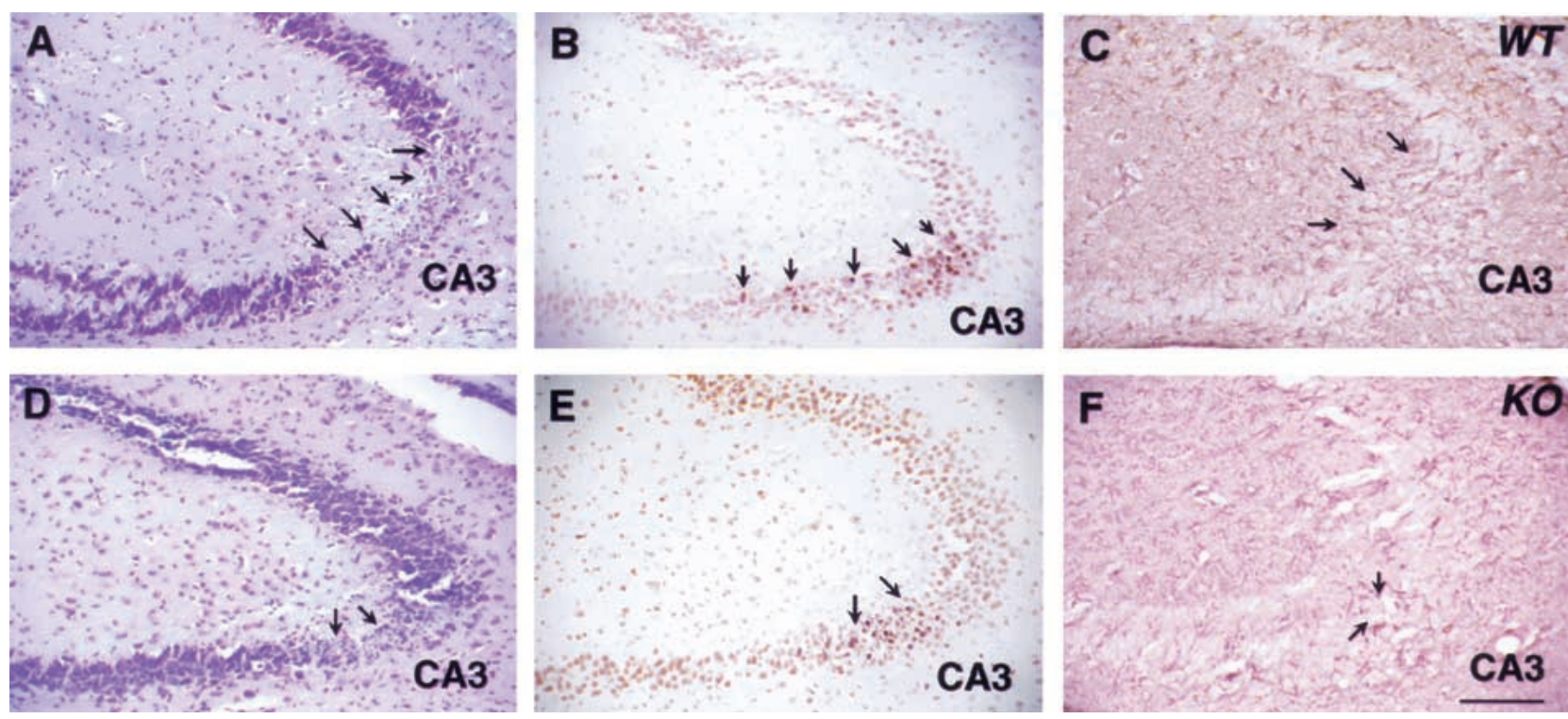

Figure 5. JIP1 deficiency causes decreased neuronal apoptosis following exposure to excitotoxic stress in vivo. Systemic kainate excitotoxicity was examined in wild-type mice $(A-C)$ and $J i p 1^{-1-}$ mice $(D-F)$. The number of animals with kainate-induced lesions in the CA3 subfield of the hippocampus was similar between the wild-type and Jip1 $1^{-/}$groups. The JIP1-deficient mice showed a severe reduction in the extent of kainate-induced lesions in the CA3 subfield of the hippocampus (Nissl's stain; panels $A, D$ ). The greater kainate-induced tissue damage in wild-type mice was also indicated by a wider distribution of TUNEL-positive cells $(B, E)$ and increased GFAP-positive astroglial fibers in the CA3 subfield $(C, F)$. Scale bar in $F, 100 \mu \mathrm{m}$.

cient neurons showed reduced labeling in TUNEL assays (Fig. 7E,F,I) and increased cell survival (Fig. 7G,H,J). Together, these data indicate that JIP1 contributes to JNK activation and apoptosis in neurons exposed to stress.

\section{Discussion}

\section{Scaffold protein JIP1 is a critical component of a JNK} signaling pathway

JIP1 binds to JNK, the MAP kinase kinase MKK7, and members of the mixed-lineage protein kinase group of MAP kinase kinase kinases (Whitmarsh et al. 1998). Transfection assays show that the binding of these protein kinases to JIP1 potentiates JNK activation (Whitmarsh et al. 1998). These observations indicate that JIP1 may be a scaffold protein. A critical test of this hypothesis concerns whether endogenous JIP1 is required for JNK activation. The results of the present study indicate that JIP1 deficiency can prevent stress-induced JNK activation in hippocampal neurons. Therefore, JIP1 is an essential component of a neuronal JNK signal transduction pathway. These data, together with previous biochemical studies (for review, see Davis 2000), suggest that JIP1 can function as a physiologically relevant scaffold protein that assembles a JNK signaling module.

The activation of JNK caused by the exposure of neurons to excitotoxic stress or anoxia requires JIP1 (Figs. $4,7)$. However, no difference in JNK activation between wild-type and Jip1 ${ }^{-/-}$neurons was detected following exposure to ultraviolet radiation or treatment with the drug anisomycin. Therefore, JIP1 is selectively required for JNK activation in response to specific stimuli. This selective role of the JIP1 scaffold protein in JNK activation was anticipated by previous studies of the yeast scaffold protein Ste5p, which is required for Ste $11 \mathrm{p}$ function in the mating MAP kinase pathway but is not required for Ste1lp function in the osmosensing or filamentation MAP kinase pathways (Elion 2000). The absence of an essential role for JIP1 in the response to ultraviolet radiation and anisomycin may reflect a redundant role of JIP1 (e.g., JIP2 and JIP3 are expressed in neurons) or may indicate that the activation of JNK by these stimuli is JIP-independent. The possibility that JIP1 has redundant functions may account for our failure to detect diabetes or neuronal migration defects in Jip $1^{-/-}$mice. Studies of mice with compound mutations in all of the Iip genes will be required to resolve this question. Nevertheless, our analysis of $\mathrm{Jip1}^{-/-}$mice shows that the JIP1 scaffold protein is a critical component of a JNK signal transduction pathway.

\section{Scaffold protein IIP1 is a component of a INK signaling module}

It is established that the c-Jun transcription factor is an important target of the JNK signal transduction pathway (for review, see Davis 2000). JNK phosphorylates the Nterminal domain of c-Jun and increases transcription activity. Immunofluorescence analysis showed that following exposure to stress most of the phosphorylated c-Jun protein was detected in the nucleus, where it can function as a transcription factor (Fig. 2I). Activated JNK was detected primarily in the cytoplasm surrounding the 
Whitmarsh et al.
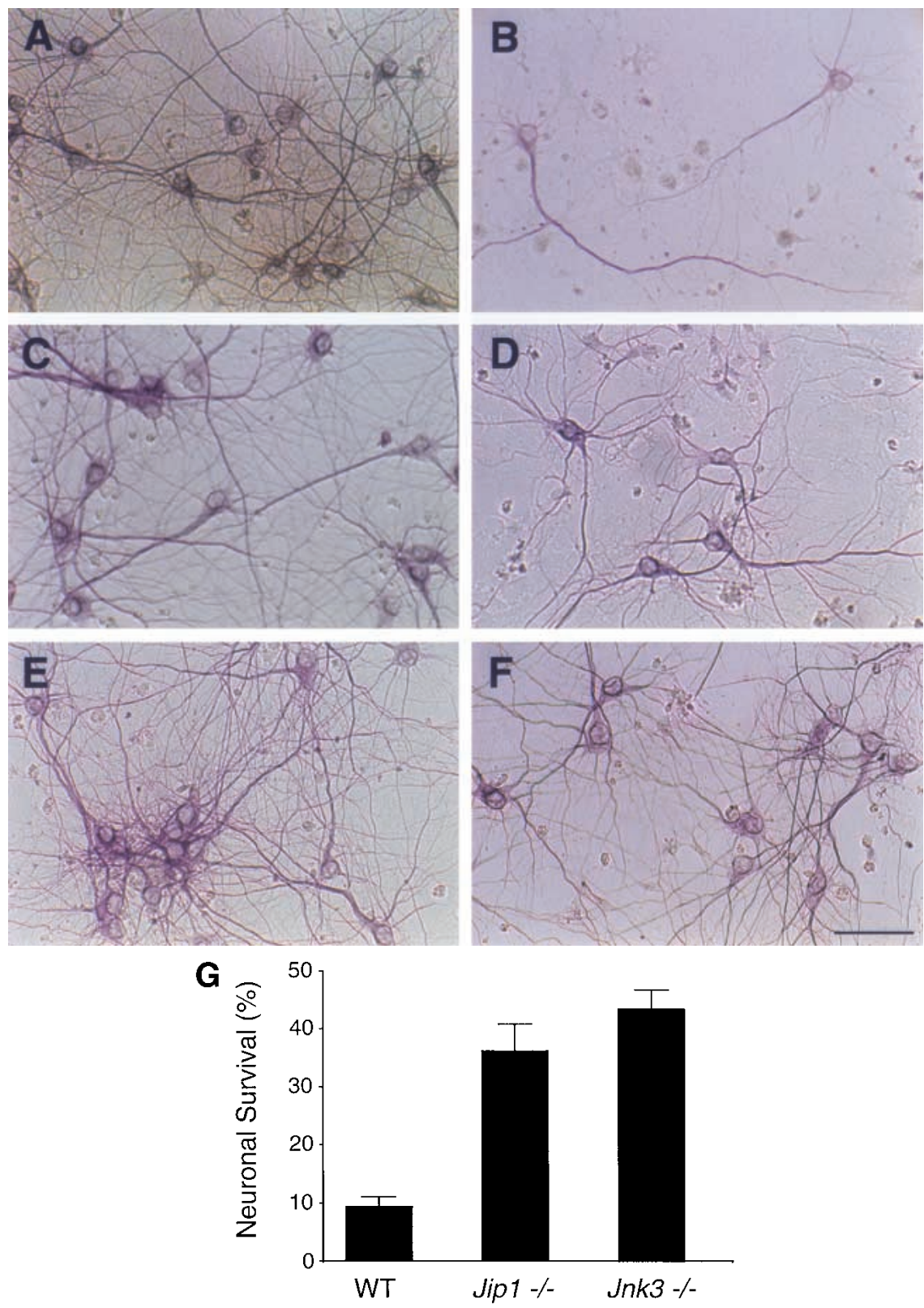

Figure 6. JIP1 deficiency causes increased survival of hippocampal neurons following exposure to excitotoxic stress in vitro. Hippocampal neurons were cultured in vitro (11 d) and treated without and with kainic acid (100 $\mu \mathrm{M} ; 30 \mathrm{~min})$. Cell survival after $24 \mathrm{~h}$ was examined by immunocytochemistry by staining neurons with an antibody to MAP-2. Representative microphotographs of unchallenged wild-type $(A)$, Jip $1^{-/-}(C)$, and Ink $3^{-/-}(E)$ neurons are presented. The effect of kainate treatment on wild-type $(B)$, Jip $1^{-/-}(D)$, and Ink3-/- $(F)$ neurons is shown. The scale bar represents $50 \mu \mathrm{m} .(G)$ Cell survival in three independent experiments was quantitated $($ mean $\pm \mathrm{SD})$.

nucleus, but some activated JNK was also observed in the nucleus (Fig. 2G). In contrast, JIP1 was primarily found in a peripheral location in the neurites of unchallenged neurons (Fig. 2A,C). Since JIP1 is required for JNK activation, it was surprising that the subcellular localization of JIP1 in neurites appeared to differ from the subcellular localization of activated JNK. However, immunofluorescence analysis showed that exposure to stress altered the subcellular distribution of JIP1. Although JIP1 was primarily located in the neurites of un- challenged neurons, JIP1 was found to accumulate in the perinuclear region of neurons following exposure to stress (Fig. 2B,D). JIP1 and activated JNK are therefore present in the same subcellular compartment following exposure to stress.

The mechanism that accounts for JIP1 localization within the cell is unclear, but it is known that JIP proteins interact with kinesin-1 (Bowman et al. 2000; Verhey et al. 2001; this study). The JIP3 protein binds via a coiled-coil domain to kinesin-1. In contrast, a small re- 

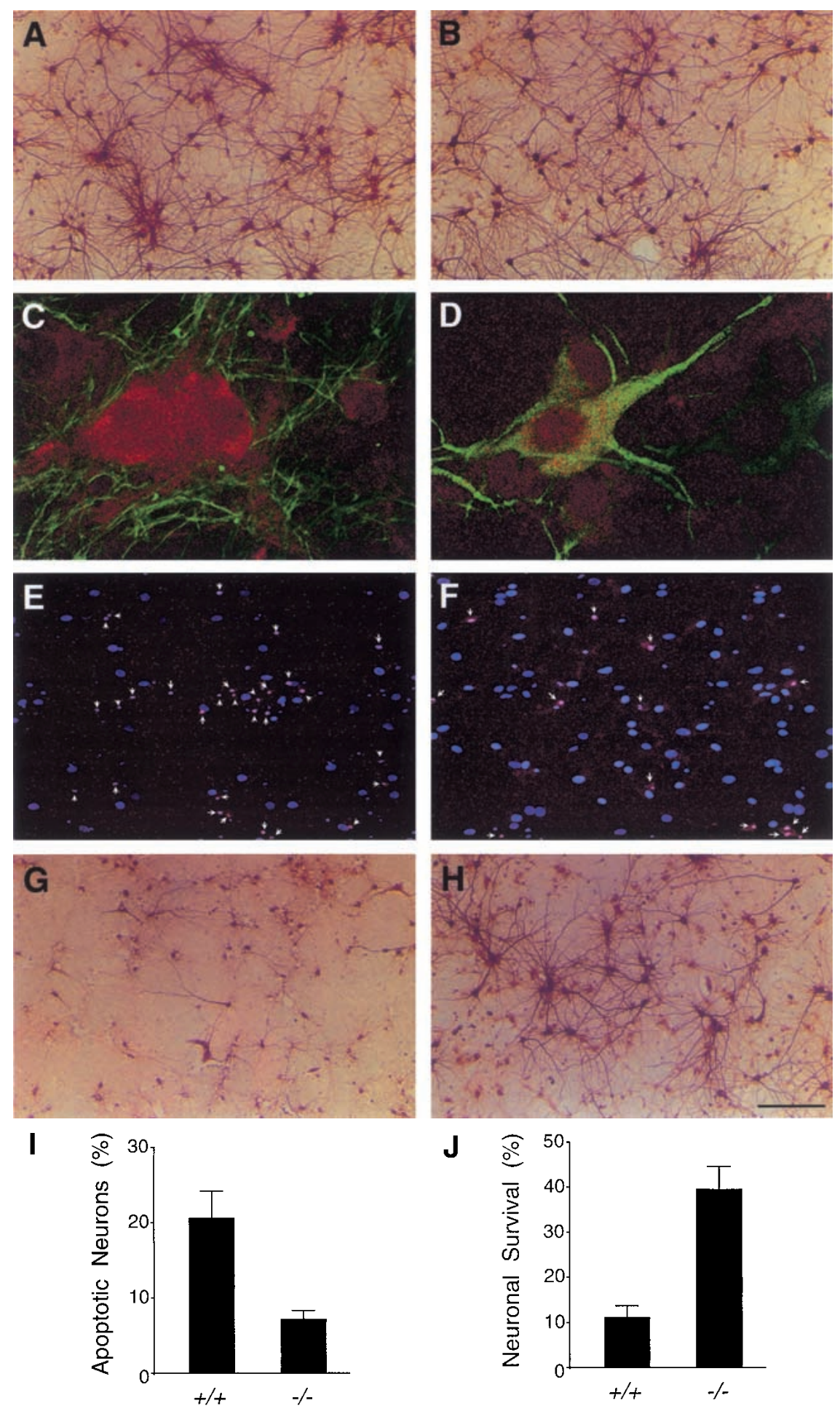
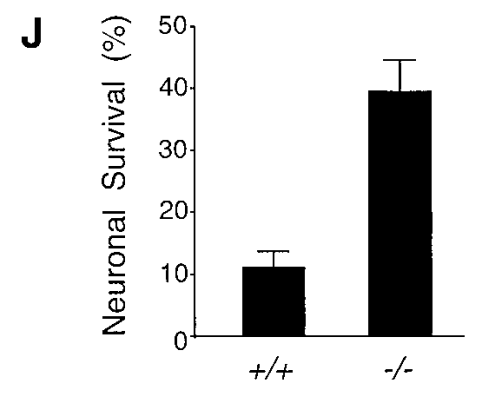

Figure 7. JIP1 deficiency causes reduced oxygen and glucose deprivation-induced JNK activation and apoptosis of hippocampal neurons. $(A, B)$ Wild-type $(A)$ and $\operatorname{Iip} 1^{-/-}$ $(B)$ hippocampal neurons were cultured in vitro and visualized by MAP2 immunocytochemistry. $(C, D)$ Activated JNK (red) was detected by immunofluorescence analysis of wild-type $(C)$ and $\operatorname{Iip} 1^{-/-}(D)$ hippocampal neurons following oxygen and glucose deprivation (OGD) challenge $(4 \mathrm{~h})$ and recovery $(12 \mathrm{~h})$ by staining with an antibody to phospho-(pThr $\left.{ }^{183} \mathrm{pTyr}^{185}\right)$ JNK. Neurites were detected by staining with an antibody to MAP2 (green). A marked increase in the amount of activated JNK was observed in wild-type neurons $(C)$, but not in Jip $1^{-/-}$neurons $(D)$ following exposure to stress. $(E, F)$ Cell death was measured by the percentage of TUNEL-positive nuclei (red) in the total number of bis-benzimide-stained nuclei (blue) following OGD challenge (4 h) and recovery $(24 \mathrm{~h})$. Increased numbers of apoptotic neurons were detected in wildtype $(E)$ compared with $\operatorname{Iip} 1^{-/-}(F)$ cultures. $(G, H)$ The survival of wild-type $(G)$ and Jip1 $1^{-/-}(H)$ hippocampal neurons was compared by MAP2 immunocytochemistry following OGD challenge $(4 \mathrm{~h})$ and recovery $(48 \mathrm{~h})$. $(I, J)$ Wild-type and Jip $1^{-/-}$hippocampal neurons were exposed to OGD challenge. Apoptosis measured by TUNEL assay $(I)$ and survival measured by MAP2 staining $(J)$ was quantitated in three independent experiments (mean $\pm \mathrm{SD}$ ). Scale bar in $H, 200 \mu \mathrm{m}$ (panels $A, B, E-H$ ) and 20 $\mu \mathrm{m}$ (panels $C, D)$. gion of the $\mathrm{C}$ terminus of JIP1 interacts with kinesin-1. Although the interaction domains of these JIP proteins are structurally distinct, the binding of each JIP protein to kinesin- 1 is mediated by the same tetratricopeptide repeat (TPR) region of kinesin light chain. The observation that JIP proteins accumulate in growth cones at the ends of extended neurites (Meyer et al. 1999; Yasuda et al. 1999; Kelkar et al. 2000) is consistent with the role of kinesin-1 as a plus end-directed microtubule motor protein. Indeed, the finding that dominant-negative kinesin-1 prevents the localization of JIP proteins to growth cones suggests that kinesin-1 may actively transport JIP proteins along microtubules (Verhey et al. 2001). Similarly, genetic analysis of JIP3 in Drosophila shows that a 
mutant allele of JIP3 (sunday driver) causes altered axonal transport (Bowman et al. 2000). Together, these data strongly support the conclusion that JIP proteins are actively transported within cells.

Although the accumulation of JIP1 in the growth cones of neurons is consistent with the known role of kinesin-1 as a plus end-directed microtubule motor protein, the mechanism that accounts for the stress-induced accumulation of JIP1 in the perinuclear region of neurons is unclear. Studies using dominant-negative kinesin light chain show inhibition of growth cone localization of JIP proteins and the redistribution of JIP proteins throughout the cytoplasm (Verhey et al. 2001). In contrast, we found that JIP1 accumulated in a punctate pattern in the perinuclear region of primary hippocampal neurons. The altered subcellular localization of JIP1 caused by stress (Fig. 2) is therefore very different from the effect of disruption of kinesin-1 function in cells.

It is possible that the altered subcellular localization of JIP1 caused by stress is mediated, in part, by a minus end-directed microtubule motor protein (e.g., cytoplasmic dynein). However, endogenous JIP1 was found to coprecipitate with kinesin-1, but not with cytoplasmic dynein under all conditions tested (N. Kelkar, unpubl.). The coprecipitation of kinesin-1 with JIP1 suggests that kinesin-1 might contribute to the perinuclear accumulation of JIP1 (using dendritic microtubules with the reverse orientation). However, this analysis does not exclude the possibility that an independent mechanism accounts for the perinuclear accumulation of JIP1 molecules in stressed cells. For example, it is possible that the perinuclear JIP1 corresponds to the localization of newly synthesized JIP1 molecules in stressed cells rather than to the redistribution of preexisting JIP1 molecules from neurites. Further studies will be required to establish the mechanisms that control the subcellular localization of JIP1 in neurons exposed to stress.

\section{Signal transduction to the nucleus}

The observation that the JIP1 protein accumulates in the perinuclear region of cells exposed to stress may be physiologically significant. Substrates of JNK include nuclear proteins (e.g., c-Jun). Accumulation of JIP1 in the perinuclear region of the cell represents a mechanism that may contribute to signal transduction from the periphery of the cell to the nucleus. A similar signaling mechanism has been proposed for target-derived neurotrophins and neurotrophin receptors that signal from the cell periphery to the nucleus (Bhattacharyya et al. 1997; Watson et al. 1999). The accumulation of JIP1 to the site of activated JNK in cells exposed to stress also exhibits some similarities to the regulation of the $\beta$-arrestin-2 scaffold, which is recruited from the cytoplasm to the cytoplasmic surface of endosomal vesicles by receptors and colocalizes with the major site of JNK activation (McDonald et al. 2000). These observations of mammalian scaffold proteins reflect previous studies of the Ste5p scaffold protein in yeast. Ste5p is recruited to the plasma membrane in response to pheromone by a mechanism that requires nuclear shuttling (Mahanty et al. 1999). The dynamic spatial regulation of Ste5p may therefore be a common property of MAP kinase scaffold proteins. In conclusion, the results of the present study indicate that the mammalian scaffold protein JIP1 is a critical component of a MAP kinase signaling pathway.

\section{Materials and methods}

Mice

$J i p 1^{-/+}$embryonic stem cells were prepared by homologous recombination and used to create mice using standard methods. The mice were back-crossed to C57BL/6 (Jackson Labs). Jip $1^{+/+}$ and $\mathrm{Jip} 1^{-/-}$littermates were obtained from matings of Jip $1^{-/+}$ mice. Glucose tolerance tests were performed using methods described previously (Leiter et al. 1988). Systemic injection of kainate $(30 \mathrm{mg} / \mathrm{kg})$ in adult mice was used to induce excitotoxic stress (Yang et al. 1997b). The brains were isolated $3 \mathrm{~d}$ after treatment with kainate and processed for paraffin embedding and histology (Yang et al. 1997b). Labeling of embryonic neurons in vivo was performed by systemic injection of BrdU at gestation day 15.5 (Haydar et al. 2000). The animals were housed in a facility accredited by the American Association for Laboratory Animal Care.

\section{Culture of primary neurons}

Cortical and hippocampal neurons were cultured from E17.5 embryos and grown in serum-free Neurobasal medium with B27 supplements (Life Technologies). Kainate treatment was performed by addition of the drug to the medium. Oxygen and glucose deprivation was performed by replacing the medium with glucose-free Earl's balanced salt solution and incubation in a tissue culture chamber with reduced oxygen $(1 \%)$ for $4 \mathrm{~h}$. The medium was replaced with Neurobasal/B27 medium and the cultures were returned to a tissue culture chamber with a normal oxygen environment.

\section{Antibodies}

JIP1, JIP2, and JIP3 antibodies have been described (Yasuda et al. 1999; Kelkar et al. 2000). The antibody to KLC1 was provided by L.S. Goldstein (University of California, San Diego). The antibodies to the Flag epitope (Sigma), $\mathrm{V}_{5}$ epitope (Invitrogen), JNK (Pharmingen), $\mathrm{pThr}^{183} / \mathrm{pTyr}^{185}$ phospho-JNK (BioSource), $\mathrm{pSer}^{73}$ phospho-c-Jun (Cell Signaling), c-Jun (Santa Cruz), MKK7 (Zymed), $\alpha$-tubulin (Sigma), $\beta$-tubulin (BabCo), MAP-2 (Sigma), and Synapsin 1 (Chemicon) were purchased from the indicated suppliers.

\section{Biochemical assays}

JNK activity was measured by an in vitro kinase assay using the substrates GST-c-Jun and $\left[\gamma_{-}{ }^{32} \mathrm{P}\right]$ ATP (Raingeaud et al. 1995). Coimmunoprecipitation assays and binding assays were performed using methods described previously (Yasuda et al. 1999; Kelkar et al. 2000).

\section{Immunofluorescence analysis}

Cells were fixed with paraformaldehyde and processed for immunofluorescence analysis (Yasuda et al. 1999). The cells were examined by fluorescence microscopy using a conventional microscope, an Axioplan2 coupled to a MicroImager CCD camera 
(Zeiss, Jena $\mathrm{GmbH}$ ). Cells were also imaged on a Zeiss LSM510NLO microscope fitted with a titanium-sapphire laser (Mira 900F) pumped by a 10-W Verdi laser (Coherent Laser Group). To enable confidence in the subcellular localization studies, care was taken to collect potentially overlapping emissions separately using the "multi-track" function. Green and red fluorophores were excited using the argon (488-nm) and $\mathrm{HeNe}$ (543$\mathrm{nm}$ ) visible lasers, respectively. Bis-benzimide was excited using the titanium-sapphire laser at $770 \mathrm{~nm}$.

\section{Acknowledgments}

We thank K. Gemme for adminstrative assistance, G. Haddad for the use of a hypoxic incubator, L.S. Goldstein for providing the KLC1 antibody, and L. Paquin for performing glucose tolerance tests. R.J.D. and R.A.F. are investigators of the Howard Hughes Medical Institute. This study was supported, in part, by research grants (CA65861 and CA85422) and by a Diabetes and Endocrinology Center grant (DK32520) from the National Institutes of Health.

The publication costs of this article were defrayed in part by payment of page charges. This article must therefore be hereby marked "advertisement" in accordance with 18 USC section 1734 solely to indicate this fact.

\section{References}

Behrens, A., Sibilia, M., and Wagner, E.F. 1999. Amino-terminal phosphorylation of c-Jun regulates stress-induced apoptosis and cellular proliferation. Nat. Genet. 21: 326-329.

Bhattacharyya, A., Watson, F.L., Bradlee, T.A., Pomeroy, S.L., Stiles, C.D., and Segal, R.A. 1997. Trk receptors function as rapid retrograde signal carriers in the adult nervous system. J. Neurosci. 17: 7007-7016.

Bonny, C., Nicod, P., and Waeber, G. 1998. IB1, a JIP-1-related nuclear protein present in insulin-secreting cells. J. Biol. Chem. 273: 1843-1846.

Bonny, C., Oberson, A., Steinmann, M., Schorderet, D.F., Nicod, P., and Waeber, G. 2000. IB1 reduces cytokine-induced apoptosis of insulin-secreting cells. J. Biol. Chem. 275: 16466-16472.

Bowman, A.B., Kamal, A., Ritchings, B.W., Philp, A.V., McGrail, M., Gindhart, J.G., and Goldstein, L.S. 2000. Kinesindependent axonal transport is mediated by the sunday driver (SYD) protein. Cell 103: 583-594.

Cheng, J., Yang, J., Xia, Y., Karin, M., and Su, B. 2000. Synergistic interaction of MEK kinase 2, c-Jun $\mathrm{N}$-terminal kinase (JNK) kinase 2, and JNK1 results in efficient and specific JNK1 activation. Mol. Cell. Biol. 20: 2334-2342.

D'Arcangelo, G., Miao, G.G., Chen, S.C., Soares, H.D., Morgan, J.I., and Curran, T. 1995. A protein related to extracellular matrix proteins deleted in the mouse mutant reeler. Nature 374: 719-723.

Davis, R.J. 2000. Signal transduction by the JNK group of MAP kinases. Cell 103: 239-252.

Derijard, B., Hibi, M., Wu, I.H., Barrett, T., Su, B., Deng, T., Karin, M., and Davis, R.J. 1994. JNK1: A protein kinase stimulated by UV light and Ha-Ras that binds and phosphorylates the c-Jun activation domain. Cell 76: 1025-1037.

Dickens, M., Rogers, J.S., Cavanagh, J., Raitano, A., Xia, Z., Halpern, J.R., Greenberg, M.E., Sawyers, C.L., and Davis, R.J. 1997. A cytoplasmic inhibitor of the JNK signal transduction pathway. Science 277: 693-696.

Dong, C., Yang, D.D., Tournier, C., Whitmarsh, A.J., Xu, J.,
Davis, R.J., and Flavell, R.A. 2000. JNK is required for effector T-cell function but not for T-cell activation. Nature 405: 91-94.

Elion, E.A. 2000. Pheromone response, mating and cell biology. Curr. Opin. Microbiol. 3: 573-581.

Ganiatsas, S., Kwee, L., Fujiwara, Y., Perkins, A., Ikeda, T., Labow, M.A., and Zon, L.I. 1998. SEK1 deficiency reveals mitogen-activated protein kinase cascade crossregulation and leads to abnormal hepatogenesis. Proc. Nat1. Acad. Sci. 95: 6881-6886.

Garrington, T.P. and Johnson, G.L. 1999. Organization and regulation of mitogen-activated protein kinase signaling pathways. Curr. Opin. Cell. Biol. 11: 211-218.

Groves, M.R. and Barford, D. 1999. Topological characteristics of helical repeat proteins. Curr. Opin. Struct. Biol. 9: 383389.

Haydar, T.F., Nowakowski, R.S., Yarowsky, P.J., and Krueger, B.K. 2000. Role of founder cell deficit and delayed neuronogenesis in microencephaly of the trisomy 3 mouse. J. Neurosci. 20: 4156-4164.

Hollenbeck, P.J. 2001. Kinesin delivers. Identifying receptors for motor proteins. J. Cell Biol. 152: F25-F28.

Ito, M., Yoshioka, K., Akechi, M., Yamashita, S., Takamatsu, N., Sugiyama, K., Hibi, M., Nakabeppu, Y., Shiba, T., and Yamamoto, K.I. 1999. JSAP1, a novel jun N-terminal protein kinase (JNK)-binding protein that functions as a scaffold factor in the JNK signaling pathway. Mol. Cell. Biol. 19: 75397548.

Kelkar, N., Gupta, S., Dickens, M., and Davis, R.J. 2000. Interaction of a mitogen-activated protein kinase signaling module with the neuronal protein JIP3. Mol. Cell. Biol. 20: 10301043.

Kyriakis, J.M., Banerjee, P., Nikolakaki, E., Dai, T., Rubie, E.A., Ahmad, M.F., Avruch, J., and Woodgett, J.R. 1994. The stress-activated protein kinase subfamily of c-Jun kinases. Nature 369: 156-160.

Leiter, E.H., Premdas, F., Harrison, D.E., and Lipson, L.G. 1988. Aging and glucose homeostasis in C57BL/6J male mice. FASEB J. 2: 2807-2811.

Mahanty, S.K., Wang, Y., Farley, F.W., and Elion, E.A. 1999. Nuclear shuttling of yeast scaffold Ste5 is required for its recruitment to the plasma membrane and activation of the mating MAPK cascade. Cell 98: 501-512.

McDonald, P.H., Chow, C.W., Miller, W.E., Laporte, S.A., Field, M.E., Lin, F.T., Davis, R.J., and Lefkowitz, R.J. 2000. $\beta$-Arrestin 2: A receptor-regulated MAPK scaffold for the activation of JNK3. Science 290: 1574-1577.

Meyer, D., Liu, A., and Margolis, B. 1999. Interaction of c-Jun amino-terminal kinase interacting protein-1 with p190 rhoGEF and its localization in differentiated neurons. J. Biol. Chem. 274: 35113-35118.

Miller, W.E. and Lefkowitz, R.J. 2001. Expanding roles for $\beta$-arrestins as scaffolds and adapters in GPCR signaling and trafficking. Curr. Opin. Cell Biol. 13: 139-145.

Nath, R., Probert, A., Jr., McGinnis, K.M., and Wang, K.K. 1998. Evidence for activation of caspase-3-like protease in excitotoxin- and hypoxia/hypoglycemia-injured neurons. J. Neurochem. 71: 186-195.

Negri, S., Oberson, A., Steinmann, M., Sauser, C., Nicod, P., Waeber, G., Schorderet, D.F., and Bonny, C. 2000. cDNA cloning and mapping of a novel islet-brain/JNK-interacting protein. Genomics 64: 324-330.

Nishina, H., Fischer, K.D., Radvanyi, L., Shahinian, A., Hakem, R., Rubie, E.A., Bernstein, A., Mak, T.W., Woodgett, J.R., and Penninger, J.M. 1997. Stress-signalling kinase Sek1 protects thymocytes from apoptosis mediated by CD95 and CD3. Na- 
ture 385: 350-353.

Pellet, J.B., Haefliger, J.A., Staple, J.K., Widmann, C., Welker, E., Hirling, H., Bonny, C., Nicod, P., Catsicas, S., Waeber, G., et al. 2000. Spatial, temporal and subcellular localization of islet-brain 1 (IB1), a homologue of JIP-1, in mouse brain. Eur. J. Neurosci. 12: 621-632.

Pitcher, J.A., Freedman, N.J., and Lefkowitz, R.J. 1998. G protein-coupled receptor kinases. Annu. Rev. Biochem. 67: 653-692.

Raingeaud, J., Gupta, S., Rogers, J.S., Dickens, M., Han, J., Ulevitch, R.J., and Davis, R.J. 1995. Pro-inflammatory cytokines and environmental stress cause p38 mitogen-activated protein kinase activation by dual phosphorylation on tyrosine and threonine. J. Biol. Chem. 270: 7420-7426.

Simonian, N.A., Getz, R.L., Leveque, J.C., Konradi, C., and Coyle, J.T. 1996. Kainate induces apoptosis in neurons. Neuroscience 74: 675-683.

Stockinger, W., Brandes, C., Fasching, D., Hermann, M., Gotthardt, M., Herz, J., Schneider, W.J., and Nimpf, J. 2000. The reelin receptor ApoER2 recruits JNK-interacting proteins-1 and 2. J. Biol. Chem. 275: 25625-25632.

Swat, W., Fujikawa, K., Ganiatsas, S., Yang, D., Xavier, R.J., Harris, N.L., Davidson, L., Ferrini, R., Davis, R.J., Labow, M.A., et al. 1998. SEK1/MKK4 is required for maintenance of a normal peripheral lymphoid compartment but not for lymphocyte development. Immunity 8: 625-634.

Tournier, C., Hess, P., Yang, D.D., Xu, J., Turner, T.K., Nimnual, A., Bar-Sagi, D., Jones, S.N., Flavell, R.A., and Davis, R.J. 2000. Requirement of JNK for stress-induced activation of the cytochrome c-mediated death pathway. Science 288: 870-874.

Tournier, C., Dong, C., Turner, T.K., Jones, S.N., Flavell, R.A., and Davis, R.J. 2001. MKK7 is an essential component of the JNK signal transduction pathway activated by proinflammatory cytokines. Genes \& Dev. 15: 1419-1426.

Trommsdorff, M., Gotthardt, M., Hiesberger, T., Shelton, J., Stockinger, W., Nimpf, J., Hammer, R.E., Richardson, J.A., and Herz, J. 1999. Reeler/disabled-like disruption of neuronal migration in knockout mice lacking the VLDL receptor and ApoE receptor 2. Cell 97: 689-701.

Verhey, K.J., Meyer, D., Deehan, R., Blenis, J., Schnapp, B.J., Rapoport, T.A., and Margolis, B. 2001. Cargo of kinesin identified as JIP scaffolding proteins and associated signaling molecules. J. Cell Biol. 152: 959-970.

Waeber, G., Delplanque, J., Bonny, C., Mooser, V., Steinmann, M., Widmann, C., Maillard, A., Miklossy, J., Dina, C., Hani, E.H., et al. 2000. The gene MAPK8IP1, encoding islet-brain1 , is a candidate for type 2 diabetes. Nat. Genet. 24: 291-295.

Watson, F.L., Heerssen, H.M., Moheban, D.B., Lin, M.Z., Sauvageot, C.M., Bhattacharyya, A., Pomeroy, S.L., and Segal, R.A. 1999. Rapid nuclear responses to target-derived neurotrophins require retrograde transport of ligand-receptor complex. J. Neurosci. 19: 7889-7900.

Whitmarsh, A.J. and Davis, R.J. 1998. Structural organization of MAP-kinase signaling modules by scaffold proteins in yeast and mammals. Trends Biochem. Sci. 23: 481-485.

Whitmarsh, A.J., Cavanagh, J., Tournier, C., Yasuda, J., and Davis, R.J. 1998. A mammalian scaffold complex that selectively mediates MAP kinase activation. Science 281: 1671-1674.

Xia, Y., Wu, Z., Su, B., Murray, B., and Karin, M. 1998. JNKK1 organizes a MAP kinase module through specific and sequential interactions with upstream and downstream components mediated by its amino-terminal extension. Genes \& Dev. 12: 3369-3381.

Xia, Z., Dickens, M., Raingeaud, J., Davis, R.J., and Greenberg, M.E. 1995. Opposing effects of ERK and JNK-p38 MAP ki- nases on apoptosis. Science 270: 1326-1331.

Yang, D., Tournier, C., Wysk, M., Lu, H.T., Xu, J., Davis, R.J., and Flavell, R.A. 1997a. Targeted disruption of the MKK4 gene causes embryonic death, inhibition of c-Jun $\mathrm{NH}_{2}$-terminal kinase activation, and defects in AP-1 transcriptional activity. Proc. Natl. Acad. Sci. 94: 3004-3009.

Yang, D.D., Kuan, C.Y., Whitmarsh, A.J., Rincon, M., Zheng, T.S., Davis, R.J., Rakic, P., and Flavell, R.A. 1997b. Absence of excitotoxicity-induced apoptosis in the hippocampus of mice lacking the Ink3 gene. Nature 389: 865-870.

Yasuda, J., Whitmarsh, A.J., Cavanagh, J., Sharma, M., and Davis, R.J. 1999. The JIP group of mitogen-activated protein kinase scaffold proteins. Mol. Cell. Biol. 19: 7245-7254. 


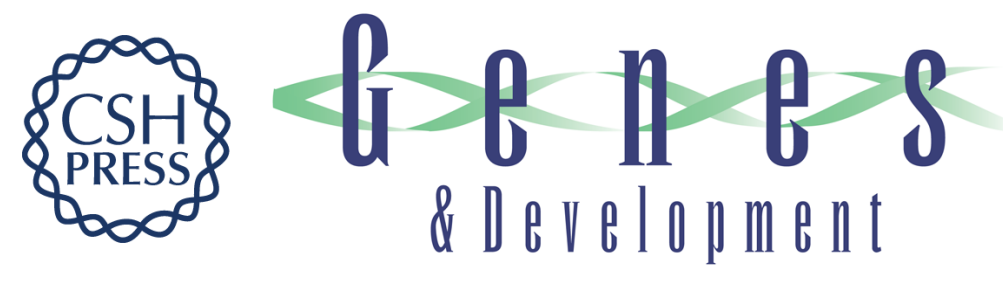

\section{Requirement of the JIP1 scaffold protein for stress-induced JNK activation}

Alan J. Whitmarsh, Chia-Yi Kuan, Norman J. Kennedy, et al.

Genes Dev. 2001, 15:

Access the most recent version at doi:10.1101/gad.922801

References This article cites 47 articles, 23 of which can be accessed free at: http://genesdev.cshlp.org/content/15/18/2421.full.html\#ref-list-1

License

Email Alerting

Receive free email alerts when new articles cite this article - sign up in the box at the top Service right corner of the article or click here.

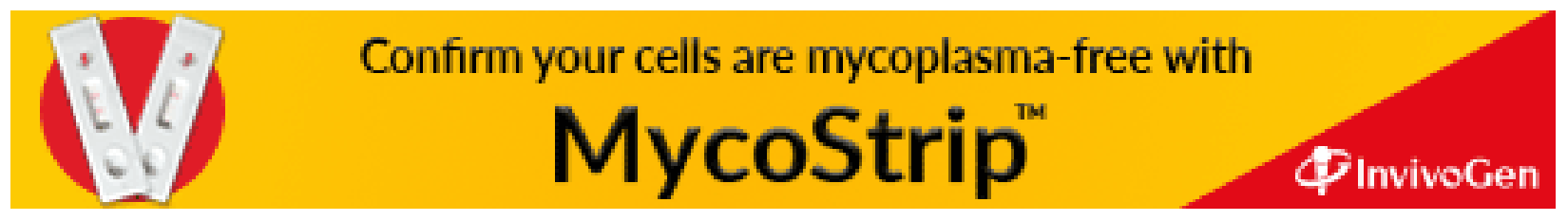

